\title{
COMBINING FUZZY LOGIC AND INFORMATION THEORY FOR PRODUCING A LANDSLIDE SUSCEPTIBILITY MODEL
}

\author{
Tsangaratos P. ${ }^{1}$ and Ilia $\mathbf{I}^{1}{ }^{1}$
}

${ }^{1}$ National Technical University of Athens, School of Mining and Metallurgical Engineering, Department of Geological Science, Iroon Polytechniou 9, Zografou 15780, Athens, Greece, ptsag@metal.ntua.gr,gilia@metal.ntua.gr

\begin{abstract}
The main objective of the present study was to develop a landslide susceptibility model by combining Fuzzy logic and Information Theory in order to estimate the spatial probability of landslide manifestation, in the mountains of central Tzoumerka, Greece. Specifically, Fuzzy logic was enabled for weighting the landslide related variables based on expert knowledge and in respect to landslide susceptibility, while the Shannon's entropy index, an index from Information Theory, was calculated to weight the significance of each landslide related variable based on the available data. The final landslide susceptibility map was produced by applying the weighted sum method. Engineering lithological units, slope angle, slope aspect, distance from tectonic features, distance from river network and distance from road network were among the six landslide related variables that were included in the landslide database used in the training phase. The landslide inventory map was constructed by interpreting aerial photographs, satellite images and field surveys and was separated into two datasets, one for training and one for validating the model. The outcomes of the validation process illustrated that the developed methodology efficiently provided the most susceptible areas and was in good agreement with the actual landslide locations. The area under the curve was estimated to be for the training and validating datasets 0.7575 and 0.7828 respectively. The produced landslide susceptibility map could be regarded from local and national authorities as a valuable mean to evaluate strategies or to prevent and mitigate the impact of landslides.
\end{abstract}

Keywords: slope stability, fuzzy weighting, Shannon's entropy index, Tzoumerka, Greece.

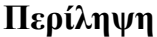

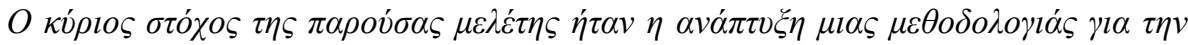

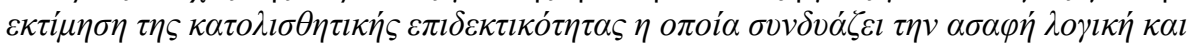

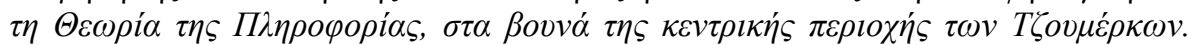

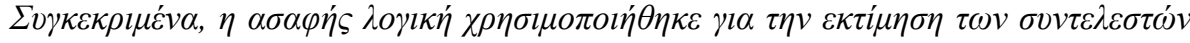

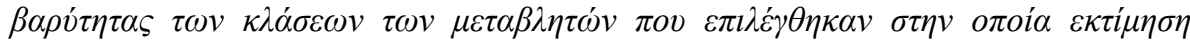

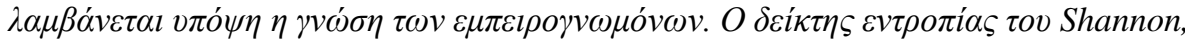

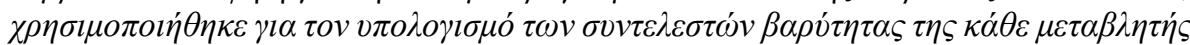

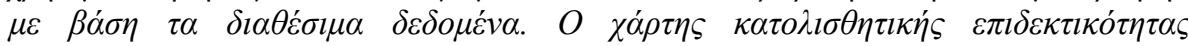

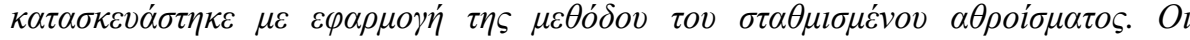

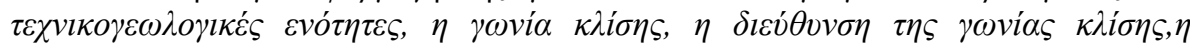

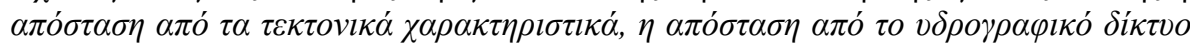

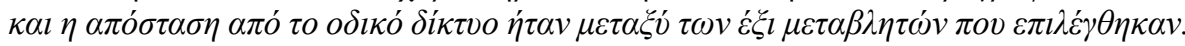




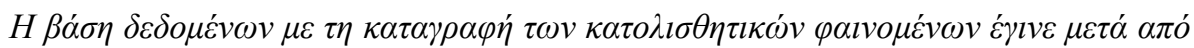

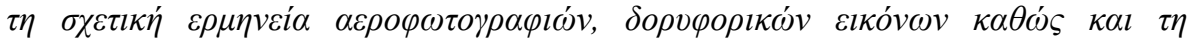
$\delta l \varepsilon \xi \alpha \gamma \omega \gamma \eta \dot{~ \varepsilon \rho \varepsilon v v \omega ́ v ~ \pi \varepsilon \delta i ́ o v . ~ X \omega \rho i ́ \tau \tau \eta \kappa \varepsilon ~ \sigma \varepsilon ~ \delta v ́ o ~ \sigma o ́ v o \lambda \alpha ~ \delta \varepsilon \delta о \mu \varepsilon ́ v \omega v, ~ \varepsilon ́ v \alpha ~ \gamma l \alpha ~ \varepsilon \kappa \pi \alpha i ́ \delta \varepsilon v \sigma \eta ~}$

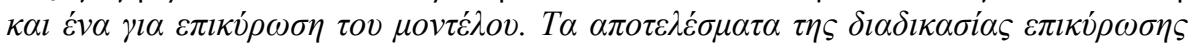

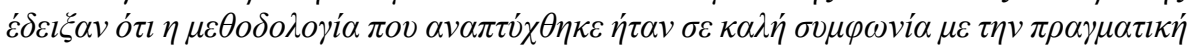

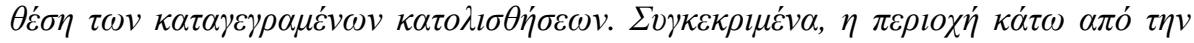

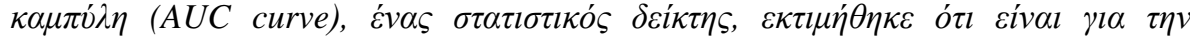

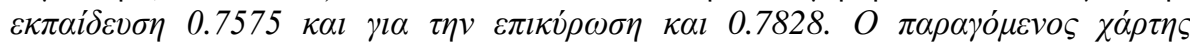

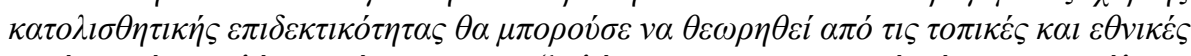

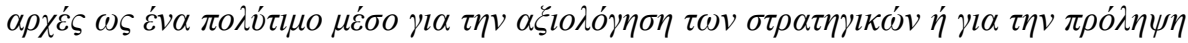

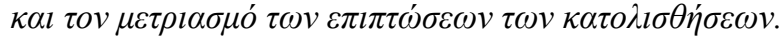

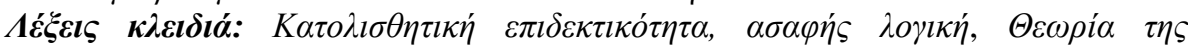

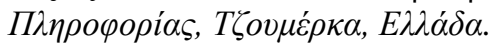

\section{Introduction}

Landslides involve a wide variety of processes that result in the gravitational movement of slopeforming materials that may occur in offshore, coastal or/and inland areas. They are considered among the most frequent natural hazards with significant consequences to human life and incalculable social - economic consequences. Its general accepted that natural hazards cannot be prevented; however their impacts can be reduced. In this context, the spatial distribution of future landslides that is estimated during a landslide susceptibility analysis provides information and knowledge that aids land - use planning, decision making and overall landslide risk reduction. Thus, the estimation of the likelihood of a landslide occurring in an area is a fundamental process defined by a set of geological, tectonic and hydrologic conditions, morphological characteristics, soil and vegetation features, land use and human practices. The analysis of landslide phenomenon is attempted through qualitative or expert - driven models and quantitative or data - driven models. Relatively recently, new techniques and methods derived from the domain of Machine Learning and Data Mining where utilized as promising tools to evaluate the susceptibility and risk against landslides (Korup and Stolle, 2014). These methods are characterized by the ability of learning and discovering hidden and unknown patterns from large multi-thematic databases. Numerous papers could be found through the scientific literature that take advantage of their ability to sufficiently assess data, including: the logistic regression approach (Pourghasemi et al., 2013a; Regmi et al., 2014), fuzzy logic method (Pourghasemi et al., 2012a; Tien Bui et al., 2012a; Feizizadeh and Blaschke, 2013; Zhu et al., 2014), artificial neural network method (Ermini et al., 2005; Ferentinou and Sakellariou 2007; Yilmaz 2010; Tien Bui et al., 2012b; Conforti et al., 2014; Tsangaratos and Benardos, 2014), Bayes theorem based on weights of evidence (Regmi et al., 2010a, 2010b; Kouli et al., 2014; Ilia and Tsangaratos 2015), neural-fuzzy method (Vahidnia et al., 2010; Oh and Pradhan, 2011), support vector machines (Yilmaz 2010; Tien Bui et al., 2012c; Pourghasemi et al., 2013b; Pradhan 2013), index of entropy (Bednarik et al., 2010; Constantin et al., 2011; Pourghasemi et al., 2012b; Devkota et al., 2013; Youssef et al., 2015) and decision tree method (Saito et al., 2009; Yeon et al.,2010; Nefeslioglu et al., 2010; Tien Bui et al., 2012c; Pradhan, 2013; Tsangaratos and Ilia, 2015). The main objective of the present study is to produce a landslide susceptibility map based on the combination of Fuzzy logic and Information Theory. The Fuzzy logic approach was applied in order to weight the variables according to expert opinion, while the Information Theory was applied to estimate the influence of each variable has on the landslide susceptibility calculation based on the data. The study area covers the mountains of Central Tzoumerka, which are located at the administrative unit of Epirus Greece, where serious landslides events have been encountered. The computation process was carried out using SPSS 16.0 (SPSS, 2007) for validating the model, while ArcGIS 10.1 (ESRI, 2013) was used for compiling the data and producing the landslide susceptibility maps. 


\section{Study area}

The main research area is located at the eastern part of the Pindus administrative unit covering approximately an area of $222 \mathrm{~km}^{2}$ clarified as the Kallaritikos watershed, a sub - basin of the Greek Water District Epirus (Fig. 1a).

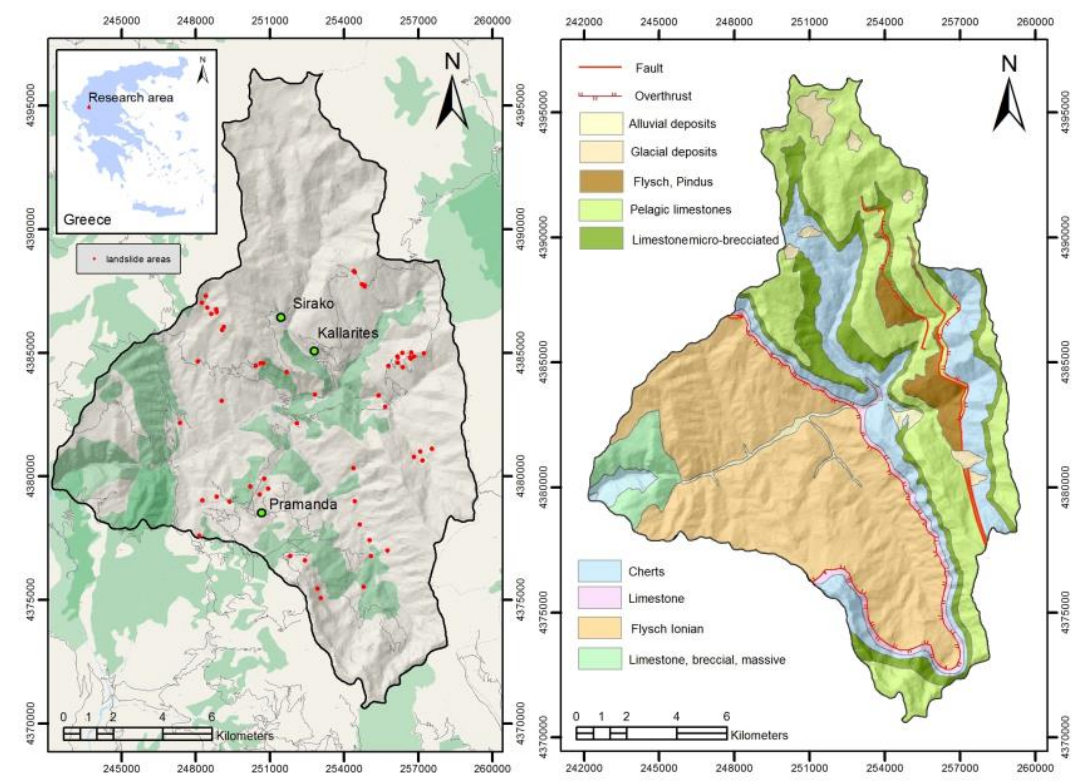

Figure 1a - The study area, 1b - The geology of the area.

Concerning the topography of the area it's characterized as mountainous, with the highest altitude observed in the area reaching $2354 \mathrm{~m}$ while the lowest point is at $325 \mathrm{~m}$ above sea level. The geological profile of the wider region consists of formations that are part of the Ionian tectonic zone, mainly constituted by Upper Eocene - Lower Miocene sedimentary sequences, as well as part of the Pindus tectonic zone, where Upper Cretaceous - Eocene sedimentary sequences outcrop (Brunn, 1956; Aubouin, 1959). About $43.40 \%$ of the research area is covered by chert formations with limestone interbeds, $37.20 \%$ covered by limestone formations and about $17.35 \%$ covered by flysch formations. The area is characterized by a dense dendritic drainage pattern, while large successive anticlines and synclines overthrusts to the west.

\section{Materials and Methods}

\subsection{The developed methodology}

The developed methodology consisted of a four phase procedure; (a) classifying and weighting the predictor variables based on fuzzy logic and expert knowledge, (b) calculating the weight of each variable based on the Shannon's entropy index, (c) applying the weighted sum model to produce the landslide susceptibility map and (d) validating the produced model. Details of each phase are provided in the following paragraphs. The first phase, involves the application of a fuzzy logic approach in order to estimate the weight of each predictor variable. The developed methodology collects the opinions of a group of experts in reference to the importance each predictor factor has to the estimation of landslide susceptibility. Each expert assigns a linguistic value (very important, quiet important, important, neutral, unimportant, quite unimportant and very unimportant) when asked about the importance of the factor that is transformed into a triangular fuzzy number (Table 1). 
Table 1 - Scale of importance.

\begin{tabular}{|c|c|}
\hline Intensity of importance & Fuzzy triangular number \\
\hline Very important (VI) & $(1,2,3)$ \\
\hline Quiet important $(\mathrm{QI})$ & $(2,3,4)$ \\
\hline Important $(\mathrm{I})$ & $(3,4,5)$ \\
\hline Neutral $(\mathrm{N})$ & $(4,5,6)$ \\
\hline Unimportant $(\mathrm{UnI})$ & $(5,6,7)$ \\
\hline Quite unimportant(QUnI) & $(6,7,8)$ \\
\hline Very unimportant (VUnI) & $(7,8,9)$ \\
\hline
\end{tabular}

The aggregated triangular fuzzy number is calculated using the geometric mean model of mean general model proposed by Klir and Yuan (1995). The computing formula is illustrated as follows:

Assume the linguistic value assigned to the $\mathrm{j}^{\text {th }}$ predictor factor $(\mathrm{j}=1,2 \ldots \mathrm{n})$ by the $\mathrm{i}^{\text {th }}$ expert $(\mathrm{i}=1,2, . . \mathrm{k})$ and the equivalent triangular fuzzy number that corresponds to that linguistic value $v_{i j}=\left(a_{i j}, b_{i j}, c_{i j}\right)$

The aggregated triangular fuzzy number for the $\mathrm{j}^{\text {th }}$ predictor factor is $\tilde{v}_{j}=\left(a_{j}, b_{j}, c_{j}\right)$ where, $a_{j}=\underset{i=1}{\stackrel{k}{M}\left\{a_{i j}\right\}} \quad b_{j}=\frac{1}{n} \sum_{i=1}^{k} b_{i j} \quad c_{j}=\underset{i=1}{\operatorname{Max}}\left\{c_{i j}\right\}$

The next step is to use the simple centre of gravity method to defuzzify the aggregated triangular fuzzy number of each predictor factor and to estimate the Intensity of importance $\left(\mathrm{I}_{\mathrm{j}}\right)$ (Equation 1), while the weighting of each predictor variable is obtained by the equation 2 .

\section{Equation 1 - Intensity of importance}

$$
I_{j}=\frac{a_{j}+b_{j}+c_{j}}{3}
$$

\section{Equation 2 - Weight of variables}

$w i_{j}=\frac{\max \left\{I_{j}\right\}-I_{j}+1}{\sum_{k=1}^{n} \max \left\{I_{j}\right\}-I_{k}+1}$

The next phase involves the estimation of weight of influence of each variable based on Shannon's entropy index. The Shannon's entropy index has been used in the Information Theory as a measure originally proposed by Claude Shannon to quantify the entropy, uncertainty or information content in strings of text (Shannon, 1948). It proposes that the more information one has the more certain one becomes, likewise we can postulate that the more diverse something is the more uncertain we become in knowing its decision or outcome. The information coefficient is an index that ranges between 0 and 1 , with values closer to 0 indicating less influence of the variable while values closer to 1 indicating more influence. The equations used to calculate the information coefficient $\mathrm{Wj}$ representing the weight value for the parameter as a whole (Bednarik et al., 2010; Constantin et al., 2011) are given in Table 2. 
Table 2 - Equation for determining the Weight coefficient based on Shannon's entropy index.

\begin{tabular}{|l|l|c|}
\hline $\begin{array}{c}\text { Number of } \\
\text { equation }\end{array}$ & \multicolumn{1}{|c|}{ Explanation } & Equation \\
\hline Equation 3 & Landslide probability & $p_{i j}=\frac{L_{i j}}{A_{i j}}$ \\
\hline Equation 4 & Landslide Probability density & $P_{i j}=\frac{p_{i j}}{c_{j}}$ \\
\hline Equation 5 & Entropy value & $\sum_{j=1} p_{i j}$ \\
\hline Equation 6 & Maximum entropy value & $H_{j}=-\sum_{i=1}^{c_{j}} P_{i j} \otimes \log _{2} P_{i j}$ \\
\hline Equation 7 & Information coefficient & $H_{j \max }=-\log _{2} c_{j}$ \\
\hline Equation 8 & Weight coefficient of each class of $\mathrm{j}^{\text {th } \text { factor }}$ & $I_{j}=\frac{H_{j \max }-H_{j}}{H_{j}}$ \\
\hline
\end{tabular}

The third phase involves the application of the weighted sum method in order to calculate the landslide susceptibility index, according to equation 9:

\section{Equation 3 - Landslide susceptibility index}

$L S i_{p i}=\frac{1}{j} \sum_{j=1}^{n} w_{i j} * w i_{c i j}$

The result of the summation is a continuous interval of values which represent the various levels of susceptibility and forms the landslide susceptibility map that is reclassified according to the natural break method for the determination of the class intervals (Feizizadeh and Blaschke, 2013). Classes identified are described as follows: very high susceptibility (VHS), high susceptibility (HS), moderate susceptibility (MS), low susceptibility (LS) and very low susceptibility (VLS). The final phase involves the validation of the developed model by means of the success-rate and predictionrate methods (Fawcett, 2006). Using the landslide grid cells in the training dataset, the success-rate results were obtained, while the validation dataset were used for the construction of the predictionrate curves (Chung and Fabbri, 2003). The area under the ROC curve (AUC) has been used as a metric to access the overall quality of the predictive models by evaluating the models ability to anticipate correctly the occurrence or non-occurrence of predefined events (Hanley and McNeil, 1982; Fawcett, 2006). If AUC is close to 1, the outcomes of the analysis are excellent, while if the $\mathrm{AUC}$ is closer to 0.5 , the less accurate the result of the analysis is.

\subsection{Data}

Concerning the landslide inventory which includes information about the location, features and abundance of landslide areas, it was based on historical information concerning landslide incidence, the interpretation of aerial photos, the use of satellite imagery and extensive field observations. A total of 116 sites where identified and partitioned into two datasets, one for training and one for validating purpose, containing 93 and 23 sites, respectively. The landslide related variables that was selected for the assessment of the landslide susceptibility of the research area are described by the following six variables: engineering geological units, slope angle, slope aspect, distance from tectonic features, distance from river network and distance from road network. Particular, the 
geological formations that cover the research area were grouped into four categories based on their engineering geological behavior, the spatial distribution of failures identified in the region, but also the experience and knowledge that has been recorded in related studies. Specifically, the following were found and classified: A) quaternary loose, fine grained deposits that consist mainly of cobbles, pebbles, grits and sands with low proportions of fines, such as clayey silts and sandy silts; B) limestones formations, that are characterized as Pelagic, thin to medium - bedded, often micro brecciated with nodules or lenticular silica layers and local thin intercalations of shales; C) flysch formations with alternating siltstones and sandstones and frequent participation of conglomerates and intermediate lithological types, and D) chert formations with limestone interbeds. The fault density maps were also constructed based on the geological map (IGME, 1961) and was classified into three zones of influence: A) $<250 \mathrm{~m}$, B) 251-500m and C) $>501 \mathrm{~m}$. A digital elevation model (DEM) with a spatial resolution of $20 \times 20 \mathrm{~m}$ was generated from national topographic maps in scale 1:50.000. Based on the DEM data, slope angle, slope aspect and distance from the river network were constructed. Specifically, five classes for slope angle have been identified and classified: A) $0^{0}-15^{0}$, B) $16^{0}-30^{\circ}$, C) $31^{0}-45^{0}$, D) $46^{0}-60^{\circ}$ and E) slopes greater than $61^{\circ}$. In accordance to the previous, five classes for slope aspect have been identified and classified: A) $226^{\circ}-270^{\circ}$, B) $46^{0}-90^{\circ}$, C) $91^{\circ}-135^{\circ}, 271^{0}-315^{\circ}$, and D) $316^{\circ}-45^{\circ}, 136^{\circ}-225^{\circ}$ (Fig.4d). Concerning the river network density map, it was formed using the DEM data and further classified into three zones of influence: A) < $100 \mathrm{~m}, \mathrm{~B}) 101-300 \mathrm{~m}$, and C) $>301 \mathrm{~m}$. Finally, the distance from the road network was constructed based on the national topographic maps and classified into three zones of influence, characterizing the distance of landslide incidence from the road network: A) < 100m, B) 101-300m, and C) > 301m.

\section{Results}

According to the weighting process conducted in the first phase (Table 2), that was based on fuzzy logic and expert knowledge, the most susceptible class was estimated to be class A $(<100 \mathrm{~m})$ in the variable Distance to road network $(0.5714)$, followed by the class A $(<100 \mathrm{~m})$ in the variable Distance to river network (0.5000). The least susceptible class was class A $\left(<15^{\circ}\right)$ in the variable Slope $(0.0667)$, followed by the class A $\left(226^{0}-270^{\circ}\right)$ in the variable Aspect $(0.1000)$. From the analysis performed during the second phase (Table 3), that was based on the Information Theory and the Shannon index, the most uncertain variable was estimated to be Distance to river network (0.0133), followed by Aspect (0.0307), Engineering lithological units (0.0490), Slope (0.1426), Distance to tectonic features (0.3995) and Distance to road network (0.4087).

Table 4 - Weight of variables according to expert knowledge and Information Theory.

\begin{tabular}{|c|c|c|c|}
\hline Landslide related variable & Class & $\begin{array}{c}\text { Fuzzy Logic } \\
\mathbf{W}_{\mathbf{j}} \\
\end{array}$ & $\begin{array}{c}\text { Information Theory } \\
w_{\mathrm{ij}} \\
\end{array}$ \\
\hline \multirow[t]{4}{*}{ Engineering lithological units } & $\mathrm{A}$ & 0.1176 & 0.0490 \\
\hline & B & 0.1765 & \\
\hline & $\mathrm{C}$ & 0.3529 & \\
\hline & $\mathrm{D}$ & 0.3529 & \\
\hline \multirow[t]{5}{*}{ Slope } & $\mathrm{A}$ & 0.0667 & 0.1426 \\
\hline & B & 0.1667 & \\
\hline & $\mathrm{C}$ & 0.2000 & \\
\hline & $\mathrm{D}$ & 0.3000 & \\
\hline & $E$ & 0.2667 & \\
\hline \multirow[t]{3}{*}{ Aspect } & $\mathrm{A}$ & 0.1000 & 0.0307 \\
\hline & B & 0.1667 & \\
\hline & $\mathrm{C}$ & 0.2000 & \\
\hline
\end{tabular}




\begin{tabular}{|c|c|c|c|}
\hline Landslide related variable & Class & $\begin{array}{c}\text { Fuzzy Logic } \\
\mathbf{W}_{\mathbf{j}}\end{array}$ & $\begin{array}{c}\text { Information Theory } \\
\mathbf{w}_{\mathbf{i j}}\end{array}$ \\
\hline & $\mathrm{D}$ & 0.2667 & \\
\hline & $\mathrm{E}$ & 0.1333 & \\
\hline Distance to tectonic features & $<250 \mathrm{~m}$ & 0.4737 & 0.3995 \\
\hline & $251-500 \mathrm{~m}$ & 0.4211 & \\
\hline & $>501 \mathrm{~m}$ & 0.1053 & \\
\hline Distance to river network & $<100 \mathrm{~m}$ & 0.5000 & 0.0133 \\
\hline & $101-300 \mathrm{~m}$ & 0.3571 & \\
\hline & $>301 \mathrm{~m}$ & 0.1429 & \\
\hline Distance to road network & $<100 \mathrm{~m}$ & 0.5714 & 0.4087 \\
\hline & $101-300 \mathrm{~m}$ & 0.4286 & \\
\hline & $>301 \mathrm{~m}$ & 0.2143 & \\
\hline
\end{tabular}

The third phase involved the application of the weighted sum method in order to calculate the landslide susceptibility index, according to equation 9. The outcome of the estimation is illustrated in Figure 2a in which the various levels of susceptibility are presented and reclassified according to the natural break method for the determination of the class intervals. Following the developed methodology five classes of susceptibility where identified. Very high susceptibility (VHS) that covered approximately $8.59 \%$, high susceptibility (HS) covering $20.42 \%$, moderate susceptibility (MS) covering 29.65\%, low susceptibility (LS) covering $27.29 \%$ and very low susceptibility (VLS) covering $14.05 \%$ of the total research area. As illustrated in figure $2 \mathrm{~b}$, the landslide probability density within the zones high and very high susceptibility was calculated to be over $81.00 \%$, while within the zones very low and low susceptibility was calculated to be less than 5\%. The results of the implementation of the developed methodology was validated using the training and validation dataset through the use of the ROC graphs and the success and prediction rate curves, which are summarized by the calculation of AUC values. Figure $2 \mathrm{~b}$ shows the results indicating that the model has good prediction capabilities. In particular, the AUC value for the training and validating datasets was calculated to be 0.7575 and 0.7828 respectively.

\section{Discussion and conclusion}

It is well established that for the assessment of landslide phenomena, the majority of the applied methods are based either on the experience and knowledge provided by experts or on statistical or probabilistic theories or even the use of deterministic models (Aleotti and Chowdhury, 1999). Each procedure has advantages and disadvantages that are influenced by the quality and quantity of the available data and also the experience, judgment and the time engagement of the expert. In this context, the development of a hybrid method that combines the two procedures can be thought as a valuable tool in order to produce more accurate predictive models. Particularly, in the present study a landslide susceptibility map was produced by applying Fuzzy logic and Information Theory. The Fuzzy logic approach was applied in order to weight the variables according to expert opinion, while the Information Theory was applied to estimate the influence of each variable has on the landslide susceptibility calculation based on the data. 

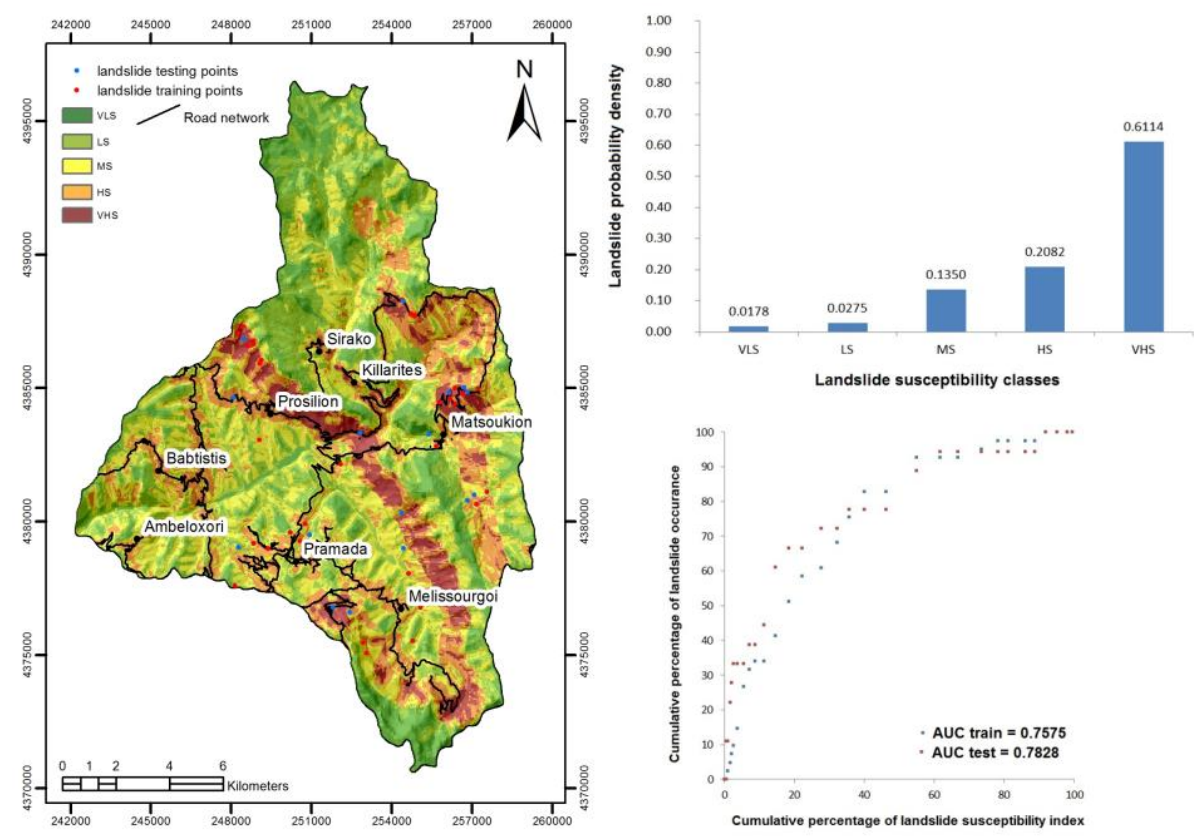

Figure 2a - The landslide susceptibility map, 2b - Validation graphs.

The study area covers the mountains of Central Tzoumerka, an area considered as one of the historical centres of the Vlach culture in Pindus, Greece, with a cluster of significant historical villages, such as Sirako, Killarites and Pramanda. From the visual inspection of the produced landslide susceptibility map it is obvious that the spatial pattern of susceptibility mainly follows the spatial distribution of the landslide conditioning variable, Distance to tectonic features. Furthermore, major sections of the road network that connect those historical villages intersect areas of very high landslide susceptibility. Concerning the accuracy of the developed model, the combination of the two procedures produced highly accurate predictive models. Specifically, the AUC value for the training and validating datasets was 0.7575 and 0.7828 respectively. In conclusion, the produced landslide susceptibility map could be regarded from local and national authorities as a valuable mean to evaluate strategies or to prevent and mitigate the impact of landslides.

\section{References}

Aleotti, P. and Chowdhury, R., 1999. Landslide hazard assessment: summary review and new perspectives, Bulletin of Engineering Geology and the Environment, 58, 21-44.

Aubouin, J., 1959. Contribution a l' etude geologique de la Grece septentrionale: les confins de l' Epire et de la Thessalie, Ann. Geol. Pays Hellen., 10, 1-483.

Bednarik, M., Magulova, B., Matys, M. and Marschalko, M., 2010. Landslide susceptibility assessment of the Kralovany-Liptovsky Mikulas railway case study, Phys Chem Earth Parts $A / B / C, 35(3-5), 162-171$.

Brunn, J.H., 1956. Contribution à l'étude géologique du Pinde septentrional et d'une partie de la Macédoine occidentale, Annales géol. pays hellén.,1re série, 7, 358 pp., 20 pl.

Chung, C.J.F. and Fabbri, A.G., 2003. Validation of spatial prediction models for landslide hazard mapping, Natural Hazards, 30(3), 451-472.

Conforti, M., Pascale, S., Robustelli, G. and Sdao, F., 2014. Evaluation of prediction capability of the artificial neural networks for mapping landslide susceptibility in the Turbolo River catchment northern Calabria, Italy, Catena, 113, 236-250. 
Constantin, M., Bednarik, M., Jurchescu, MC. and Vlaicu, M., 2011. Landslide susceptibility assessment using the bivariate statistical analysis and the index of entropy in the Sibiciu Basin (Romania), Environ Earth Sci., 63, 397-406.

Devkota, K.C., Regmi, A.D., Pourghasemi, H.R., Yoshida, K., Pradhan, B., Ryu, I.C., Dhital, M.R. and Althuwaynee, O.F., 2013. Landslide susceptibility mapping using certainty factor, index of entropy and logistic regression models in GIS and their comparison at MuglingNarayanghat road section in Nepal Himalaya, Natural Hazards, 65, 135-165.

Ermini, L., Catani, F. and Casagli, N., 2005. Artificial neural networks applied to landslide susceptibility assessment, Geomorphology, 66, 327-343.

ESRI, 2013. ArcGIS Desktop: Release 10.1 Redlands, CA: Environmental Systems Research Institute.

Fawcett, T., 2006. An introduction to ROC analysis, Pattern Recognition Letters, 27, 861-874.

Feizizadeh, B. and Blaschke, T., 2013. GIS-multicriteria decision analysis for landslide susceptibility mapping: comparing three methods for the Urmia lake basin, Iran, Natural Hazards, 65(3), 2105-2128.

Ferentinou, M. and Sakellariou, M., 2007. Computational intelligence tools for the prediction of slope performance, Computers and Geotechnics, 34, 362-384.

Hanley, J.A. and McNeil, B.J., 1982. The meaning and use of the area under a receiver operating characteristic (ROC) curvek, Radiology, 143(1), 29-36.

IGME, 1961. Geological Map of Greece, Sheet Pramanda, 1:50.000, Athens, I.G.M.E. Publications.

Ilia, I. and Tsangaratos, P., 2015. Applying weight of evidence method and sensitivity analysis to produce a landslide susceptibility map, Landslides, doi: 10.1007/s10346-015-0576-3.

Klir, G.J. and Yuan, B., 1995. Fuzzy sets and fuzzy logic: theory and applications, Prentice-Hall.

Korup, O. and Stolle, A., 2014. Landslide prediction from machine learning, Geology Today, 30(1), 26-33.

Kouli, M., Loupasakis, C., Soupios, P., Rozos, D. and Vallianatos, F., 2014. Landslide susceptibility mapping by comparing the WLC and WofE multi-criteria methods in the West Crete Island, Greece, Environ Earth Sci., doi: 10.1007/s12665-014-3389-0.

Nefeslioglu, H.A., Sezer, E., Gokceoglu, C., Bozkir, A.S. and Duman, T.Y., 2010. Assessment of landslide susceptibility by decision trees in the metropolitan area of Istanbul, Turkey, Math Probl Eng., doi: 10.1155/2010/901095, Article ID 901095.

Oh, H.J. and Pradhan, B., 2011. Application of a neuro-fuzzy model to landslide susceptibility mapping in a tropical hilly area, Computers \& Geosciences, 37(3), 1264-1276.

Pourghasemi, H.R, Moradi, H.R. and Fatemi Aghda, S.M., 2013a. Landslide susceptibility mapping by binary logistic regression, analytical hierarchy process, and statistical index models and assessment of their performances, Natural Hazards, 69(1), 749-779.

Pourghasemi, H.R., Jirandeh, A.G., Pradhan, B., Xu, C. and Gokceoglu, C., 2013b. Landslide susceptibility mapping using support vector machine and GIS at the Golestan Province, Iran, J. Earth Syst. Sci., 122(2), 349-369.

Pourghasemi, H.R., Mohammady, M. and Pradhan, B., 2012b. Landslide susceptibility mapping using index of entropy and conditional probability models in GIS: Safarood Basin, Iran, Catena, 97, 71-84. doi: 10.1016/j.catena.2012.05.005.

Pourghasemi, H.R., Pradhan, B. and Gokceoglu, C., 2012a. Application of fuzzy logic and analytical hierarchy process (AHP) to landslide susceptibility mapping at Haraz watershed, Iran, Natural Hazards, 63(2), 965-996.

Pradhan, B., 2013. A comparative study on the predictive ability of the decision tree, support vector machine and neuro-fuzzy models in landslide susceptibility mapping using GIS, Computers \& Geosciences, 51, 350-365.

Regmi, N.R., Giardino, J.R., McDonald, E.V. and Vitek, J.D., 2014. A comparison of logistic regression based models of susceptibility to landslides in western Colorado, USA, Landslides, 11, 247-262.

Regmi, N.R., Giardino, J.R. and Vitek, J.D., 2010a. Modeling susceptibility to landslides using the weight of evidence approach: Western Colorado, USA, Geomorphology, 115, 172-187. 
Regmi, N.R., Giardino, J.R. and Vitek, J.D., 2010b. Assessing susceptibility to landslides: Using models to understand observed changes in slopes, Geomorphology, 122, 25-38.

Saito, H., Nakayama, D. and Matsuyama, H., 2009. Comparison of landslide susceptibility based on a decision-tree model and actual landslide occurrence: the Akaishi mountains, Japan, Geomorphology, 109(3-4), 108-121.

Shannon, C.E., 1948. A Mathematical Theory of Communication, Bell. Syst. Technol. J., 27, 379423, SPSS, Inc. Released 2007. SPSS for Windows, Version 16.0. Chicago, SPSS Inc.

Tien Bui, D., Pradhan, B., Lofman, O., Revhaug, I. and Dick, O.B., 2012a. Spatial prediction of landslide hazards in Vietnam: A comparative assessment of the efficacy of evidential belief functions and fuzzy logic models, Catena, 96, 28-40.

Tien Bui, D., Pradhan, B., Lofman, O. and Revhaug, I., 2012c. Landslide Susceptibility Assessment in Vietnam Using Support Vector Machines, Decision Tree, and Naïve Bayes Models, Mathematical Problems in Engineering, Article ID 974638, 26 pp., doi:10.1155/2012/974638.

Tien Bui, D., Pradhan, B., Lofman, O., Revhaug, I. and Dick, O.B., 2012b. Landslide susceptibility assessment in the Hoa Binh province of Vietnam using Artificial Neural Network, Geomorphology, 171-172, 12-19.

Tsangaratos, P. and Benardos, A., 2014. Estimating landslide susceptibility through an artificial neural network classifier, Nat. Hazards, 74(3), 1489-1516.

Tsangaratos, P. and Ilia, I., 2015. Landslide susceptibility mapping using a modified decision tree classifier in the Xanthi Prefecture, Greece, Landslides, doi: 10.1007/s10346-015-0565-6.

Vahidnia, M.H., Alesheikh, A.A., Alimohammadi, A. and Hosseinali, F., 2010. A GIS-based neurofuzzy procedure for integrating knowledgeand data in landslide susceptibility mapping, Computers \& Geosciences, 36(29), 1101-1114.

Yeon, Y.K., Han, J.G. and Ryu, K.H., 2010. Landslide susceptibility mapping in Injae, Korea, using a decision tree, Engineering Geology, 16(3-4), 274-283.

Yilmaz, I., 2010. Comparison of landslide susceptibility mapping methodologies for Koyulhisar, Turkey: conditional probability, logistic regression, artificial neural networks, and support vector machine, Environ. Earth Sci., 61, 821-836.

Youssef, A.M., Pourghasemi, H.R., El-Haddad, B.A. and Dhahry, B.K., 2015. Landslide susceptibility maps using different probabilistic and bivariate statistical models and comparison of their performance at Wadi Itwad Basin, Asir Region, Saudi Arabia, Bull. Eng. Geol. Environ., doi: 10.1007/s10064-015-0734-9.

Zhu, A-X., Wang, R., Qiao J., Qin, C-Z. Chen, Y., Liu, J., Du, F., Lin, Y. and Zhu, T., 2014. An expert knowledge-based approach to landslide susceptibility mapping using GIS and fuzzy logic, Geomorphology, 214, 128-138. 